\title{
Retraction Note to: Marine oil pollution remediation and enterprise capital efficiency based on improved neural network
}

\author{
Liangbing Yang ${ }^{1}$
}

Published online: 29 November 2021

(c) Saudi Society for Geosciences 2021

Retraction Note to: Arabian Journal of Geosciences (2021) 14: 463 https://doi.org/10.1007/s12517-021-06806-Z

The Editor-in-Chief and the Publisher have retracted this article because the content of this article is nonsensical. The peer review process was not carried out in accordance with the Publisher's peer review policy. The author has not responded to correspondence regarding this retraction.

The original article can be found online at https://doi.org/10.1007/ s12517-021-06806-z.

Liangbing Yang ylbhjk639@sina.com

1 Science and Technology Finance and Mathematical Finance Key Laboratory of Sichuan Province, Business School of Sichuan University, 29 Wangjiang Road, Chengdu 610064, China 